\title{
DIMENSÕES DA REALIDADE RELACIONADAS AO PROCESSO EDUCATIVO E À TEMÁTICA AMBIENTAL PRESENTES NOS MANUAIS DOS PROFESSORES, REFERENTES AOS LIVROS DIDÁTICOS DE BIOLOGIA APROVADOS NO PNLD 2012
}

\author{
Romualdo José dos Santos 1 \\ Luciano Fernandes Silva ${ }^{2}$
}

Resumo: Neste trabalho são apresentados os resultados de uma investigação orientada pelo seguinte questionamento: que dimensões da realidade (dos conhecimentos, dos valores e da participação política) são enfatizadas pelos manuais dos professores, referentes aos livros didáticos de Biologia aprovados pelo Plano Nacional do Livro Didático - PNLD 2012 quando tratam da temática ambiental e do processo educativo? Para a análise dos dados, seguiram-se as orientações da análise categorial, uma das diferentes técnicas que compõe a denominada Análise de Conteúdo. As análises apontam que aspectos relacionados às dimensões dos conhecimentos, dos valores e da participação política são identificados nas orientações educativas que tratam da temática ambiental presentes nos manuais dos professores. A articulação entre essas três dimensões também é identificada nas orientações. Muitos são os pontos positivos identificados nas propostas educativas presentes nos manuais, porém são necessárias orientações mais claras que possibilitem abordagens mais aprofundadas e que permitam reconhecer a complexidade da temática ambiental.

Palavras-chave: Manuais dos professores. Processo educativo. Temática ambiental.

\section{DIMENSIONS OF REALITY RELATED TO THE EDUCATIONAL PROCESS AND ENVIRONMENTAL THEMES FOUND IN THE HANDBOOKS FOR TEACHERS, CONCERNING BIOLOGY TEXTBOOKS APPROVED IN PNLD 2012}

Abstract: This paper presents the results of research guided by the question: that reality dimensions (knowledge, values and political participation) are emphasized by teachers' manuals, related to Biology textbooks approved by the National Plan for Textbooks - PNLD 2012 when discussing the environmental themes and the

\footnotetext{
${ }^{1}$ Mestre em Ensino de Ciências pelo Programa de Pós Graduação em Ensino de Ciências da Universidade Federal de Itajubá - UNIFEI.

Professor efetivo da educação básica do Estado de São Paulo. Locado na Escola Estadual Professora Oscália Goes Corrêa Santos - Rio Claro - SP. romualdoprof@ yahoo.com.br

${ }^{2}$ Doutor em Educação pelo Programa de Pós Graduação em Educação da Universidade Estadual Paulista Júlio de Mesquita Filho - UNESP - Câmpus de Araraquara.

Professor Doutor Adjunto locado no Instituto de Física e Química na Universidade Federal de Itajubá UNIFEI. Atua como professor permanente no Programa de Pós Graduação em Ensino de Ciências da UNIFEI e como professor colaborador no Programa de Pós Graduação em Educação da UNESP Câmpus de Rio Claro. lufesilv@gmail.com
} 
educational process? Data were analyzed based on the Content Analysis Method, focusing on the categorical analysis. The results show that the aspects related to the dimensions of knowledge, values and political participation are identifiable in educational guidelines that address environmental issues. Furthermore, the relationship between these three dimensions is also outlined in the guidelines. However, it is necessary to improve the guidelines, allowing more in-depth approaches that address the complexity of environmental subjects.

Keywords: Teacher's manuals. Educational process. Environmental themes.

\section{LAS DIMENSIONES DE LA REALIDAD RELACIONADAS CON EL PROCESO EDUCATIVO Y LOS TEMAS AMBIENTALES PRESENTADOS EN LOS MANUALES PARA LOS MAESTROS, EN RELACIÓN CON LOS LIBROS DE TEXTO DE BIOLOGÍA APROBADOS EN PNLD 2012}

Resumen: Este artículo presenta los resultados de una investigación guiada por la siguiente pregunta: que dimensiones de la realidad (conocimientos, valores y participación política) se hacen hincapié en los manuales de los maestros, relacionados con los libros de texto de Biología aprobados por el Plan Nacional de Libros de Texto - PNLD 2012 cuando se habla de las cuestiones ambientales y el proceso educativo? Los datos fueron analizados con base en el método de Análisis de Contenido, centrándose en el análisis categorial. Los resultados muestran que los aspectos relacionados con las dimensiones del conocimiento, los valores y la participación política son identificables en las pautas educativas que se ocupan de cuestiones ambientales. Por otra parte, la relación entre estas tres dimensiones también se describe en las directrices. Sin embargo, es necesario mejorar las directrices, lo que permite enfoques más profundizados que abordan la complejidad de los problemas ambientales.

Palabras clave: Manuales para profesores. Proceso educativo. Temas ambientales

\section{A Educação Ambiental e os Livros Didáticos de Biologia}

Dentre as diferentes possibilidades de ações sociais identificadas como capazes de atuar diante dos problemas ambientais, o processo educativo é reconhecido como um importante instrumento, adequado para provocar mudanças e alterar o quadro de degradação ambiental que vem se desenvolvendo ao longo dos tempos. É nesse cenário que se concebe a expressão Educação Ambiental (EA).

De acordo com Carvalho (2011, p.51), a EA nasce com o movimento ecológico. A autora considera que "[...] a EA é herdeira direta do debate ecológico e está entre as alternativas que visam construir novas maneiras de os grupos sociais se relacionarem com o meio ambiente".

A constituição da EA, enquanto conjunto de práticas educativas, estreita suas relações com o campo da educação e, por essa razão, "[...] é da confluência entre o campo ambiental e o campo educativo com suas tradições pedagógicas que vão surgir certas orientações específicas dentro da Educação Ambiental" (CARVALHO, 2001, p. 46).

É importante considerar que diferentes concepções sobre o processo educativo 
são geradoras de uma diversidade de práticas educativas diante do quadro de degradação ambiental que se agrava a cada dia. De qualquer forma, as variadas concepções de EA apresentam alguns pontos comuns, dentre eles a preocupação com o meio ambiente e o reconhecimento da educação como sendo o principal instrumento capaz de promover melhorias na relação do ser humano com o meio ambiente (SAUVÉ, 2005).

Sobre as diferentes concepções de EA, entende-se que as mesmas podem ser classificadas, de modo bem amplo, em duas perspectivas: a EA conservadora e a EA crítica. As concepções e práticas educativas relacionadas à EA conservadora são entendidas como aquelas que não são capazes de transformar a realidade, pois reforçam a ideia de dominação do ser humano sobre a natureza (GUIMARÃES, 2004).

Para Maulin (2009), EA conservadora

[...] responde, portanto, às necessidades da manutenção do sistema econômico-político-social que gera os problemas ambientais, sendo muito mais uma educação voltada à correção e aos comportamentalismos do que ao seu enfrentamento e a formulação crítica (p.71)

Segundo Guimarães (2004), a perspectiva da EA crítica reúne concepções e práticas educativas que devem possibilitar ações que contribuam com o processo de transformação da realidade socioambiental, que se caracteriza por sua complexidade. A partir dessa perspectiva, há uma postura e um compromisso com as mudanças que possam se contrapor à lógica econômica e social da exclusão social que está articulada com processos de degradação ambiental.

Diante dessas breves considerações a respeito das perspectivas Conservadora e Crítica, nas quais as diferentes concepções e práticas de EA podem se encaixar, é importante ressaltar, como bem faz Carvalho (2006, p.22), alguns aspectos básicos relacionados às práticas educacionais voltadas para a temática ambiental, destacando que

[...] o desenvolvimento de propostas educacionais relacionadas com a temática ambiental coloca-nos diante de uma dupla tarefa, que pode ser entendida como se fosse um trabalho de identificação das duas faces de uma mesma moeda: a necessidade da clareza quanto às perspectivas, tanto em relação ao processo educativo quanto em relação à temática ambiental. Que pressupostos são eleitos para orientar as reflexões, para ancorar as simbolizações ou que justificam as decisões políticas diante da temática ambiental e do processo educativo? Que dimensões da existência humana se pretende considerar nos projetos de educação ambiental?

Diante disso, Carvalho (2006, p.22) faz a seguinte colocação:

[...] Parte-se aqui, de um pressuposto que parece estar sendo reconhecido pelo menos no plano teórico das proposições e que imprime um caráter de aproximação do ato educativo com a própria temática ambiental: trata-se do caráter político de ambas as realidades.

Repensar a relação sociedade-natureza, reconhecendo seu caráter político e cultural, possibilitou a construção de práticas educativas que, segundo Morales (2008, p.16), pudessem "[...] deflagrar ação consciente, crítica e transformadora das posturas em relação ao modo de conceber o ambiente, o mundo e seus semelhantes, assinalando possível articulação entre as ciências naturais e as ciências humanas e sociais". 
Dessa forma, tem sido cada vez mais significativo desenvolver propostas educativas que facultem a formulação crítica e o enfrentamento dos problemas ambientais o que, segundo Maulin (2009, p.71), permite "[...] problematizar as dimensões políticas, sociais e econômicas que determinam o meio ambiente", caracterizando a perspectiva da EA crítica, na qual uma abordagem interdisciplinar e que considere a complexidade das questões ambientais pode viabilizar a "[...] formação de sujeitos políticos, capazes de pensar e agir criticamente na sociedade, baseado nas vias de emancipação e transformação social” (MORALES, 2008, p.28).

Considerando a perspectiva da EA crítica como uma referência importante no planejamento e desenvolvimento de práticas educativas voltadas à temática ambiental, destaca-se o trabalho de Carvalho (2006), que apresenta princípios metodológicos que podem auxiliar na análise de trabalhos relacionados à EA. Para o autor, três dimensões devem orientar o planejamento, a elaboração e a execução de propostas educativas relacionadas à temática ambiental, no sentido de promover a formação crítica do indivíduo: a dimensão dos conhecimentos, dos valores e da participação política.

Ao se referir à dimensão dos conhecimentos, Carvalho (2006) não está considerando somente o conhecimento produzido pela atividade científica. Outras formas de conhecimento devem ser consideradas pelas propostas educativas que pretendam trabalhar as questões ambientais em sala de aula como, por exemplo, o conhecimento produzido pela Filosofia. Nesse sentido, Santana (2005) chama a atenção para o fato de que as práticas educativas voltadas para a temática ambiental, que são planejadas e executadas no ambiente escolar, devem trabalhar o conhecimento e tornálo pertinente.

As situações de degradação ambiental, provocadas por conta dos impactos diretos sofridos pelas pessoas que habitam os mais variados locais do planeta nos quais elas acontecem ou por conta de sua divulgação na mídia, permitem que as abordagens das questões ambientais em sala de aula sejam ricas de significado, por se tratar de situações vivenciadas pelos educandos, que poderão reconhecer a importância dos conhecimentos das diferentes disciplinas para compreensão e resolução dessas situações. Dessa forma, os conhecimentos passam a fazer sentido para os alunos.

As questões ambientais, portanto, permitem estabelecer conexões entre os conhecimentos prévios dos alunos e outros conhecimentos que se pretenda ensinar. Nesse sentido, tendo em conta que muitos problemas ambientais fazem parte da realidade dos alunos, é possível que estes procurem estabelecer relação entre aquilo que já sabem e o que está sendo ensinado. Partindo das reflexões de Moreira (1997) e Vasconcelos, Praia e Almeida (2003) sobre os estudos de Ausubel, o aluno pode, nesta perspectiva, reter os conhecimentos que estão sendo trabalhados, já que os mesmos associam e ancoram esse novo conhecimento em conhecimentos específicos e relevantes já presentes em sua estrutura cognitiva, condição essencial para que a aprendizagem seja considerada significativa.

A temática ambiental também se caracteriza por sua interdisciplinaridade e, por essa razão, muitas propostas de trabalho sugerem a abordagem das questões ambientais a partir da integração e interação de diversas áreas do conhecimento. Nesse tipo de trabalho deve haver uma articulação entre os conhecimentos das diferentes disciplinas. A abordagem interdisciplinar de temas relacionados ao meio ambiente pode ser uma das possibilidades de tornar o conhecimento pertinente para os alunos.

Além da dimensão dos conhecimentos, Carvalho (2006) entende como essencial o trabalho educativo que articule a dimensão dos valores éticos e estéticos. Ao trabalhar 
a questão ambiental em sala de aula, as complexas relações que se dão entre os indivíduos organizados em sociedade, e destes com a natureza, não podem ser ignoradas.

Para evitar a mistificação do conhecimento científico, é preciso considerar a dimensão dos valores, que possibilita discutir de que maneira está se dando a relação dos seres humanos, organizados em sociedade, com a natureza (CARVALHO, 2006).

Para Bonotto e Semprebone (2010, p.131), "[...] os valores têm sido considerados importante conteúdo de ensino, sobretudo ao tratarmos de certas temáticas, como a ambiental". De acordo com Bonotto (2001, p.57), "[...] os valores estão presentes em qualquer atividade, quer se dê conta disso ou não". Segundo a autora, muitos estudiosos reconhecem a importância do trabalho com valores, principalmente no que se refere às propostas educativas voltadas à temática ambiental.

Segundo Santana (2005), valores éticos e estéticos precisam ser considerados pelas propostas de ação em EA. Conforme o autor, as ações humanas que conduzem o processo de construção da humanidade devem ser orientadas por alguns valores, entre eles a liberdade, a autonomia, a justiça, a solidariedade, a tolerância, o não preconceito, o respeito ao outro e à natureza. Nesse caso, é feita uma referência aos valores éticos que precisam ser levados em conta no tratamento dos problemas ambientais que se apresentam para a humanidade.

Para Carvalho,

[...] É por meio do interesse dos diferentes seres humanos, sejam quais forem as suas realidades, em padrões éticos ou de comportamentos morais e pela necessidade de que estes sejam compreendidos na sua dimensão coletiva, que se estreitam as relações entre ética e educação (2006, p.34).

Ainda de acordo com Carvalho (2006), a degradação da natureza ou de outras formas de vida não constitui ação moralmente válida. Para o autor, é preciso assumir um compromisso ético com a vida, que leve à instituição de novos padrões de relação sociedade-natureza. O processo de formação humana deve ocupar-se da formação do sujeito ético. Esta formação ocorre "[...] pela aquisição do mais alto grau de consciência de responsabilidade social de cada ser humano, e se expressa na participação, na cooperação, na solidariedade e no respeito às individualidades e à diversidade" (RODRIGUES, 2001, p.246).

Santana (2005) chama a atenção para o fato de que é preciso que as práticas educativas voltadas à temática ambiental valorizem a contemplação do belo. Para Bonotto (2008, p.317), a incorporação dos valores estéticos por esse tipo de proposta educativa ajuda a "[...] conceber a experiência estética frente à natureza como uma possibilidade de relação desinteressada, oposta à visão sujeito-objeto, de caráter reducionista e utilitário".

Segundo Carvalho (2006, p.35):

[...] É importante que as propostas educativas relacionadas com a temática ambiental estejam atentas para a dimensão estética da natureza e estejam também atentas para a dimensão estética da própria ciência, para a "beleza" no trabalho de desvendar os mistérios do nosso mundo.

Além de considerar aspectos relacionados à dimensão dos conhecimentos e dos valores, é preciso ter em mente, como lembra Santana (2005), que a dimensão da participação política constitui um elemento importante para o tratamento adequado da 
temática ambiental por diferentes propostas educativas. Para o autor,

[...] o trato adequado da atividade em Educação Ambiental é o fato de que tais atividades não devem ser ingênuas, mas possuidoras de uma perspectiva crítica que possa intencionalmente contribuir para uma ação consequente e transformadora da realidade. Ela tem, portanto, uma dimensão política necessária (SANTANA, 2005, p.13).

Nesse sentido, cabe reforçar que

[...] a educação torna-se ação política na medida em que trabalha com a ideia de que todos os cidadãos devem ser partícipes tanto do conhecimento historicamente produzido como na reconstrução desse conhecimento para tomar as decisões em seu cotidiano de acordo com a realidade em que se situa (PEZZATO; SILVA, 2008, p.151).

A figura 1 exemplifica a condição de reciprocidade e articulação que deve existir entre as três dimensões.

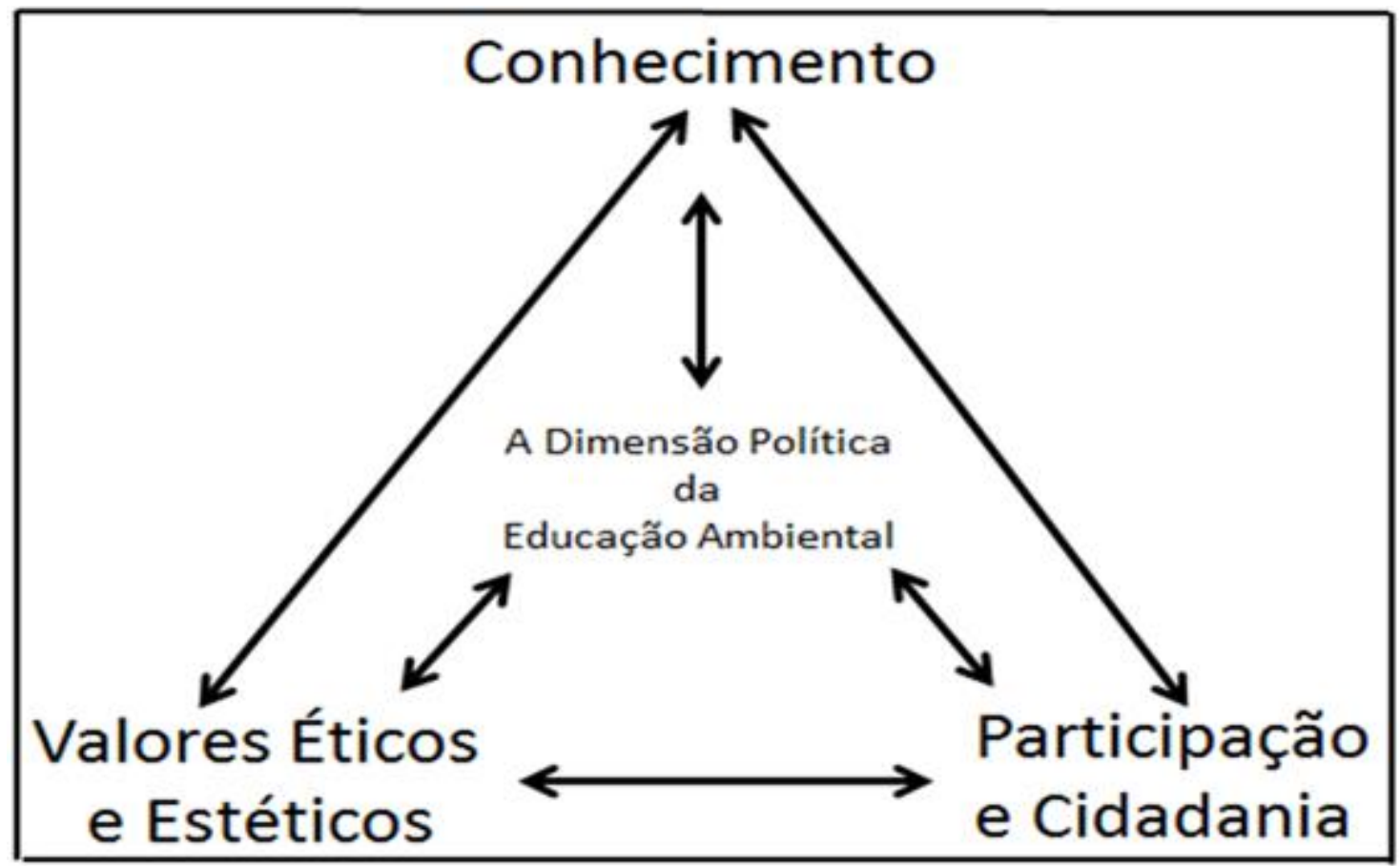

Figura 1 - Dimensões da práxis humana a serem consideradas como possíveis orientações tanto para a construção e desenvolvimento de nossos projetos de ação como para o desenvolvimento de nossas investigações em educação ambiental

Fonte: adaptado de Carvalho, 2006.

A educação deve ser compreendida como ação humana intencional, capaz de transformar a realidade. O potencial transformador da educação, resultante da prática intencional e consciente, segundo Carvalho (2006, p.36), para se concretizar, depende da "[...] participação efetiva dos seres humanos nos processos de transformação das relações sociais". Por isso, "[...] é necessário um posicionamento político, assim como ações individuais e coletivas, que possibilitem o exercício, tanto da cidadania, quanto das formas democráticas de influir e propor políticas para a educação e o meio ambiente" (CINQUETTI; CARVALHO, 2004, p.162). 
Pesquisa em Educação Ambiental, vol. 9, n. 2 - págs. 114-132, 2014

Cabe, então, considerar que

[...] a educação é uma atividade humana que permite a construção da humanidade em cada homem. É também uma atividade social uma vez que ninguém se educa sozinho, mas na relação com o outro. E é nesta relação com o outro que aprendemos a conviver e também a sermos humanos, o que faz da educação uma atividade política necessária, uma vez que a relação com o outro perpassa a convivência com o indivíduo, com o(s) grupo(s) e atinge a sociedade como um todo (SANTANA, 2005, p.1).

A citação acima indica que a dimensão da participação política deve ser central nos trabalhos e investigações relacionados à EA. A interação dessa dimensão com a dimensão dos conhecimentos e com a dimensão dos valores tem como propósito a elaboração de um modelo, ou seja, de uma tentativa aproximada de representar determinada realidade, que se caracteriza por ser um processo dinâmico em constante construção. A partir desse modelo, é possível estabelecer um princípio metodológico no qual as três dimensões (dos conhecimentos, dos valores e da participação política) se complementam e se relacionam, surgindo a possibilidade de tornar intencionais as ações educativas, o que pode ser entendido como práxis, fruto da articulação dialética entre teoria e prática (CARVALHO, 2006).

A partir desses apontamentos, vê-se a importância da elaboração de investigações que se voltem para a descrição e da compreensão sobre a forma como a EA tem sido desenvolvida nas escolas. De modo especial, compreende-se ser relevante a elaboração de investigações que se voltem para o ensino de Biologia na educação básica, por conta da estreita relação dessa disciplina com a temática ambiental, que se deve a uma tradição escolar que atribui às disciplinas que compõem a área das Ciências Naturais a responsabilidade pelo trabalho com tal temática (KRASILCHIK, 2000).

Pensando nas práticas educativas relacionadas à temática ambiental, outro ponto que precisa ser enfatizado diz respeito aos recursos utilizados pelo professor durante sua prática docente. Dentre eles, podem ser citados os livros didáticos, que têm sua distribuição garantida a todas as escolas públicas brasileiras pelo Programa Nacional do Livro Didático - PNLD.

O livro didático é portador dos conteúdos que devem ser trabalhados pelo professor junto a seus alunos. Muitas vezes, o conteúdo presente nos livros didáticos representa uma das poucas ou talvez a única oportunidade que muitos alunos têm de aprender ou entrar em contato com o conhecimento sistematizado pela Biologia. Dentre esses conhecimentos estão os relacionados aos conteúdos que abordam questões ligadas à temática ambiental. Nesse sentido, interessa ressaltar algumas formas pelas quais as questões ambientais têm sido apresentadas aos alunos e aos professores através dos livros didáticos.

Marpica (2008) apresenta um panorama das pesquisas realizadas envolvendo a educação ambiental e os livros didáticos. Nesse estudo, observou-se que as questões ambientais são abordadas de forma superficial nesses materiais. As abordagens apresentam os aspectos bióticos, abióticos e culturais de forma desarticulada. A questão social não é abordada e a questão ambiental se restringe à ecologia, sendo que, em muitos casos, questões ambientais locais são pouco abordadas ou nem mesmo aparecem. Em muitas das abordagens, prevalece um tratamento de caráter disciplinar, já que muitas vezes as questões ambientais estão presentes nos livros didáticos de Geografia e de Ciências/Biologia. 
Do modo como as questões ambientais são tratadas não é possível promover a transformação das relações com o meio ambiente, ocorrendo apenas a mera transmissão de informações, na qual prevalece a memorização de conteúdos. Ainda de acordo com as análises realizadas por Marpica (2008), os livros didáticos, quando comparados a outros materiais pedagógicos, trazem uma reflexão mais crítica, pois não ficam restritos a apontar o ser humano como grande destruidor da natureza, além de abordarem questões relativas às lacunas dos sistemas políticos e econômicos adotados pela sociedade, o que é entendido como um ponto positivo desses materiais.

Vila e Abílio (2008), por sua vez, corroboram as conclusões de Marpica (2008) ao analisarem os conteúdos referentes ao meio ambiente e à educação ambiental presentes em livros didáticos de Biologia do ensino médio publicados no período de 1990 a 2006 e que foram adotados pelas escolas públicas de João Pessoa (PB).

Silva e Souza (2011, p.12) endossam as considerações apresentadas anteriormente e ressaltam que "[...] ainda é necessário que sejam engendrados mais esforços por parte dos autores do livro didático numa interação mais forte entre os

conhecimentos biológicos e os conhecimentos relacionados às questões socioambientais".

Voichicoski e Morales (2011) fizeram uma análise de trabalhos publicados (artigos, dissertações e teses) entre os anos de 2000 e 2010 que relacionassem os temas livro didático e educação ambiental. As autoras chegaram aos seguintes resultados: nos livros didáticos predomina uma visão antropocêntrica e utilitarista das questões ambientais, e, talvez por conta disso, acaba-se observando, também, a predominância da perspectiva da educação ambiental conservadora sobre a perspectiva da educação ambiental crítica; os livros didáticos apresentam erros conceituais e assuntos desatualizados e descontextualizados, além de lacunas e inconsistências no que diz respeito aos conceitos ambientais; não atendimento das recomendações dos Parâmetros Curriculares Nacionais (PCN) e ausência de propostas educativas que promovam a participação política dos professores e educandos no tratamento das questões ambientais.

Diante do que foi exposto sobre o livro didático e sua relação com a EA e reconhecendo a importância desse recurso didático na formação dos alunos e, também, na formação dos professores, trazemos algumas considerações sobre o manual do professor, que obrigatoriamente faz parte do livro didático e que pode ajudar a compreender de que forma as questões ambientais estão sendo tratadas nos livros didáticos de Biologia.

\section{Os Manuais dos Professores dos Livros Didáticos de Biologia}

No manual do professor são apresentadas, além das orientações teóricometodológicas, sugestões de atividades, de respostas de exercícios e de leitura. Estas têm como objetivo ajudar o professor no trabalho com os conteúdos presentes no livrotexto. Contudo, segundo alguns autores (e.g AMARAL; MEGID NETO, 1997), há um descompasso entre os fundamentos conceituais e os avanços educacionais na área de Ciências apresentado nos manuais dos professores e as atividades educativas propostas explícitas ou implícitas na obra.

Paulilo (2010), em um estudo sobre os manuais dos professores dos livros didáticos de história, destaca que "[...] o Manual do Professor não é somente um aspecto da edição. Sobretudo, atende as prescrições do poder público quanto à acepção e 
organização dos dispositivos dos textos que lhe devem caracterizar" (p.11). Nesse sentido, as orientações e propostas pedagógicas e metodológicas presentes no manual contribuem para reprodução de modelos que vão de encontro aos interesses daqueles que estabeleceram os critérios para sua confecção. Por essa razão, a análise dos manuais dos professores pode contribuir com o debate sobre a forma como a temática ambiental está sendo apresentada para o professor.

O manual do professor visa promover a reflexão do professor sobre as diferentes propostas metodológicas para o ensino de Ciências/Biologia. Por isso, esse material deve apresentar articulações com o conteúdo presente no livro didático. Nesse sentido, é importante verificar quais dimensões da educação, em especial da educação ambiental, estão sendo exploradas por esse material.

A partir das reflexões apresentadas neste tópico, serão analisados e discutidos, a seguir, os dados obtidos nesta pesquisa.

Para a análise dos dados coletados nesta investigação é adotado como referencial teórico o trabalho de Carvalho (2006), que, como já descrito anteriormente, propõe a articulação entre três dimensões da realidade (dos conhecimentos; dos valores - éticos e estéticos; da dimensão da participação política), no sentido de promover a formação crítica do indivíduo.

\section{Objetivos}

As características do manual do professor motivam a investigação da sua contribuição para o trabalho com temática ambiental em sala de aula. Nesse sentido, o presente artigo apresenta resultados das análises e discussões pautadas em dados referentes às orientações de trabalho relacionadas às questões ambientais presentes nos manuais dos professores que foram conduzidas pelo seguinte questionamento: que dimensões da realidade (dos conhecimentos, dos valores e da participação política) são enfatizadas pelos manuais dos professores dos livros didáticos de Biologia aprovados pelo PNLD 2012 quando tratam da temática ambiental e do processo educativo? A partir desse questionamento, foram elaborados os seguintes objetivos específicos:

a) Identificar as características das orientações educativas presentes nos manuais dos professores dos livros didáticos de Biologia com relação às dimensões dos conhecimentos, dos valores e da participação política;

b) Analisar o grau de articulação entre essas dimensões presentes nos textos desses manuais.

\section{Procedimentos Metodológicos}

Após definir os manuais dos professores como objeto de estudo, buscou-se adquirir o material, o qual foi submetido à análise. As obras foram doadas por duas escolas públicas do Estado de Minas Gerais, localizadas nos municípios de Paraisópolis e Sapucaí Mirim.

No quadro abaixo (Quadro 1), são apresentadas as coleções aprovadas pelo PNLD 2012, na área de Ciências da Natureza e suas Tecnologias, componente curricular Biologia. O Quadro 1 também apresenta os códigos definidos para a identificação de cada coleção analisada. Esses códigos correspondem às letras iniciais dos nomes dos autores de cada coleção. Como as obras são constituídas por três volumes, foi utilizado o código, seguido do número correspondente ao volume $(1,2,3)$ 
para identificar de qual manual determinado excerto foi extraído, quando necessário.

Para análise dos dados foram adotadas algumas orientações da análise categorial, uma das diferentes técnicas que compõem a denominada Análise de Conteúdo (BARDIN, 2011), o que possibilitou a organização de agrupamentos, grupos, subgrupos a partir dos recortes feitos nos textos dos manuais dos professores.

Quadro 1 - Coleções aprovadas no PNLD 2012 Biologia e seus respectivos códigos de identificação

\begin{tabular}{|c|c|c|c|}
\hline Título da obra & Autores & Editora & Código \\
\hline Bio & Sérgio Rosso e Sônia Lopes & Saraiva & SS \\
\hline Biologia & $\begin{array}{l}\text { César da Silva Júnior, Sezar Sasson e Nelson Caldini } \\
\text { Júnior }\end{array}$ & Saraiva & CSN \\
\hline Biologia & $\begin{array}{l}\text { Antônio Pezzi, Demétrio Ossowski Gowdak e Neide } \\
\text { Simões de Mattos }\end{array}$ & FTD & $\mathrm{ADN}$ \\
\hline $\begin{array}{l}\text { Biologia para a } \\
\text { nova geração }\end{array}$ & $\begin{array}{l}\text { V. Mendonça e J. Laurence } \\
\end{array}$ & $\begin{array}{c}\text { Nova } \\
\text { Geração }\end{array}$ & VJ \\
\hline Biologia & José Mariano Amabis e Gilberto Rodrigues Martho & Moderna & JG \\
\hline Biologia hoje & $\begin{array}{c}\text { Sérgio de Vasconcellos Linhares e Fernando } \\
\text { Gewandsnajder }\end{array}$ & Ática & SF \\
\hline $\begin{array}{l}\text { Novas bases da } \\
\text { Biologia }\end{array}$ & Nélio Bizzo & Ática & $\mathrm{N}$ \\
\hline $\begin{array}{l}\text { Ser protagonista } \\
\text { Biologia }\end{array}$ & $\begin{array}{l}\text { Fernando Santiago dos Santos; João Batista Vicentin } \\
\text { Aguilar; Maria Martha Argel de Oliveira (orgs.) }\end{array}$ & SM & FJM \\
\hline
\end{tabular}

Uma das orientações da análise categorial, seguida nesta pesquisa, foi a préanálise que se caracteriza, segundo Bardin (2011), por ser a fase da organização. A escolha dos documentos e a formulação dos objetivos representam tarefas que são executadas nesse polo da análise categorial. Nessa fase, foram feitas várias leituras flutuantes do texto, a fim de

[...] estabelecer contato com os documentos a analisar e em conhecer o texto deixando-se invadir por impressões e orientações. (...) Pouco a pouco, a leitura vai se tornando mais precisa, em função das hipóteses emergentes, das projeções das teorias adaptadas sobre o material e da possível aplicação de técnicas utilizadas sobre materiais análogos (BARDIN, 2011, p.126).

De acordo com Oliveira et al. (2003), a leitura flutuante permite ao pesquisador se apropriar de forma gradual do texto, processo que se torna possível graças ao movimento de idas e vindas que se dá entre o documento submetido à leitura e as anotações do pesquisador.

A partir dessas leituras, foram destacados dos textos dos manuais dos professores dos livros didáticos de Biologia excertos que apresentavam relação com questões referentes à temática ambiental. É importante destacar que os objetivos específicos desta pesquisa possibilitaram a realização de vários recortes nos textos dos manuais, já que a partir deles foram realizadas leituras dos manuais dos professores com a intenção de se obter dados significativos que pudessem indicar a relação com esses objetivos.

Durante a leitura, foram recortados e arquivados, com a ajuda de um editor eletrônico, trechos dos textos que faziam menção explícita ou implícita às orientações de trabalho que estivessem relacionadas a práticas educativas voltadas à temática ambiental. Nesses trechos, buscou-se identificar características relacionadas às dimensões dos conhecimentos, dos valores e da participação política, conforme orientação do referencial teórico. As características relacionadas às três dimensões 
foram apresentadas e discutidas de forma separada.

Em um primeiro momento, as análises se voltaram para os dados relacionados à dimensão dos conhecimentos, buscando compreender a relevância dessa dimensão para o tratamento das questões ambientais. Em seguida, foi adotado o mesmo procedimento para tratar dos dados relacionados às dimensões dos valores e da participação política.

Finalizada a análise e discussão dos resultados referentes aos dados correspondentes às características das três dimensões identificadas nas orientações e propostas de atividades presentes nos manuais, o próximo passo foi analisar se existia articulação entre as três dimensões.

A partir dos objetivos específicos desta pesquisa, foram construídos agrupamentos, que auxiliaram na interpretação dos dados coletados. Quanto à definição de categorias, ficou compreendido que cada um dos itens que se referem às características relacionadas às três dimensões, e o item no qual se discute a articulação entre essas dimensões, podem ser considerados categorias deste trabalho que foram estabelecidas a priori.

As categorias, segundo Bardin (2011), são os conjuntos de elementos de significação que são constituídos pelas unidades de sentido. As unidades de sentido, neste trabalho, podem ser caracterizadas pelos fragmentos de texto retirados dos manuais dos professores analisados.

\section{Resultados e Discussão}

A análise dos manuais possibilitou organizar os dados dentro de quatro categorias: dimensão dos conhecimentos, dimensões dos valores, dimensão da participação política e relação entre as três dimensões.

A categoria dimensão dos conhecimentos é formada pelos seguintes agrupamentos: perspectiva interdisciplinar, conhecimentos ligados às Ciências Naturais, conhecimentos ligados às Ciências Humanas, outros conhecimentos e saberes.

Nas orientações educativas identificadas nos manuais, foi observado que estes materiais reconhecem a importância de propostas pedagógicas em uma perspectiva interdisciplinar para o tratamento das questões ambientais. O Quadro 2 apresenta as disciplinas que podem contribuir com trabalhos dessa natureza.

Entende-se que essa preocupação com propostas de trabalhos interdisciplinares pode ser considerada um avanço importante para o tratamento das questões ambientais em sala de aula. Para Carvalho (2011), esse tratamento deve permitir a coordenação e a cooperação entre os conhecimentos das diferentes disciplinas. Essa prática pedagógica pode ajudar professores e alunos a reconhecerem a importância das diferentes formas de conhecimento no enfrentamento de situações que estejam ligadas à temática ambiental.

Quadro 2 - Disciplinas que fazem parte das orientações de trabalho que sugerem a abordagem dos temas ambientais a partir de uma perspectiva interdisciplinar

\begin{tabular}{|l|c|c|c|c|c|c|c|c|}
\hline \multirow{2}{*}{ Disciplinas } & \multicolumn{7}{|c|}{ Coleções analisadas } \\
\cline { 2 - 9 } & SS & CSN & ADN & VJ & JG & SF & N & FJM \\
\hline Educação artística/arte & $\mathrm{X}$ & & & X & & & & \\
\hline Filosofia & & & & & X & & & \\
\hline Física & $\mathrm{X}$ & $\mathrm{X}$ & & & $\mathrm{X}$ & $\mathrm{X}$ & & $\mathrm{X}$ \\
\hline Geografia & $\mathrm{X}$ & $\mathrm{X}$ & $\mathrm{X}$ & $\mathrm{X}$ & $\mathrm{X}$ & $\mathrm{X}$ & $\mathrm{X}$ & $\mathrm{X}$ \\
\hline História & & & $\mathrm{X}$ & & & $\mathrm{X}$ & $\mathrm{X}$ & $\mathrm{X}$ \\
\hline Matemática & & $\mathrm{X}$ & & & & $\mathrm{X}$ & $\mathrm{X}$ & \\
\hline Português & $\mathrm{X}$ & & $\mathrm{X}$ & $\mathrm{X}$ & & & $\mathrm{X}$ & $\mathrm{X}$ \\
\hline
\end{tabular}




\begin{tabular}{|l|c|c|c|c|c|c|c|c|}
\hline Química & $\mathrm{X}$ & $\mathrm{X}$ & & $\mathrm{X}$ & & & $\mathrm{X}$ & $\mathrm{X}$ \\
\hline Sociologia & & & & & & $\mathrm{X}$ & & $\mathrm{X}$ \\
\hline
\end{tabular}

Os conhecimentos específicos - Biologia (Bio); Física (Fis); Química (Qui); Matemática (Mat); Geografia (Geo); História (Hist); Arte; Português (Port) - e saberes - conhecimentos prévios (CP) e conhecimentos populares (Pop) caracterizam os outros três agrupamentos (Quadro 3).

Quadro 3 - Conhecimentos específicos e outros saberes que caracterizam os agrupamentos relacionados a dimensão dos conhecimentos e sua presença nos manuais das oito coleções analisadas

\begin{tabular}{|l|c|c|c|c|c|c|c|c|c|c|}
\cline { 2 - 12 } \multicolumn{1}{c|}{} & \multicolumn{9}{|c|}{$\begin{array}{c}\text { Conhecimentos ligados a } \\
\text { Ciências da Natureza }\end{array}$} & \multicolumn{3}{c|}{$\begin{array}{c}\text { Conhecimentos ligados a } \\
\text { Ciências Humanas }\end{array}$} & \multicolumn{3}{c|}{$\begin{array}{c}\text { Outros conhecimentos e } \\
\text { saberes }\end{array}$} \\
\hline Coleções & Bio. & Fis. & Qui. & Mat. & Geo. & Hist. & Arte & Port. & CP. & Pop. \\
\hline SS & $\mathrm{X}$ & $\mathrm{X}$ & $\mathrm{X}$ & $\mathrm{X}$ & $\mathrm{X}$ & & $\mathrm{X}$ & $\mathrm{X}$ & & \\
\hline CSN & $\mathrm{X}$ & & $\mathrm{X}$ & $\mathrm{X}$ & $\mathrm{X}$ & $\mathrm{X}$ & & & & $\mathrm{X}$ \\
\hline ADN & $\mathrm{X}$ & & $\mathrm{X}$ & & $\mathrm{X}$ & $\mathrm{X}$ & & $\mathrm{X}$ & & \\
\hline VJ & $\mathrm{X}$ & & $\mathrm{X}$ & $\mathrm{X}$ & $\mathrm{X}$ & & $\mathrm{X}$ & $\mathrm{X}$ & & \\
\hline JG & $\mathrm{X}$ & & $\mathrm{X}$ & & $\mathrm{X}$ & $\mathrm{X}$ & & & & \\
\hline SF & $\mathrm{X}$ & $\mathrm{X}$ & $\mathrm{X}$ & & $\mathrm{X}$ & & & & $\mathrm{X}$ & \\
\hline N & $\mathrm{X}$ & $\mathrm{X}$ & $\mathrm{X}$ & $\mathrm{X}$ & $\mathrm{X}$ & $\mathrm{X}$ & & $\mathrm{X}$ & & \\
\hline FJM & $\mathrm{X}$ & $\mathrm{X}$ & $\mathrm{X}$ & & $\mathrm{X}$ & $\mathrm{X}$ & & $\mathrm{X}$ & $\mathrm{X}$ & \\
\hline
\end{tabular}

Sobre o quadro 3 é importante destacar que os conhecimentos específicos de Biologia e Química (Ciências Naturais), juntamente com os conhecimentos específicos da Geografia (Ciências Humanas) são identificados nas orientações educativas que tratam da temática ambiental nos manuais dos professores. Nessas orientações também é possível dizer que os aspectos biológicos/ecológicos predominam nas propostas educativas que tratam das questões ambientais. Carvalho $(2011$, p.158) salienta que um dos objetivos das propostas educativas voltadas para a temática ambiental deve ser o de

[...] promover a compreensão dos problemas socioambientais em suas múltiplas dimensões: geográficas, históricas, biológicas, sociais e subjetivas; considerando o ambiente como o conjunto das inter-relações que se estabelecem entre o mundo natural e o mundo social, mediado por saberes locais e tradicionais, além dos saberes científicos.

Nos manuais, podem ser observadas orientações que se caracterizam por abordagens conceituais e factuais. Para superar tais abordagens, Carvalho (1989) sugere abordagens ecológico-evolutivas, nas quais sejam estabelecidas relações entre transformações geológicas e as transformações biológicas, o que possibilitaria uma compreensão mais ampla e significativa dos temas ambientais relacionados à abordagem evolutiva. Orientações com essas características podem ajudar tanto professores quanto alunos no reconhecimento da complexidade da temática ambiental.

Nas orientações educativas presentes nos manuais, foi identificada, como mostra o Quadro 3, a presença de diferentes conhecimentos sistematizados e, de forma mais tímida, a presença de outros saberes, dentre os quais podem ser destacados os conhecimentos prévios (C.P.) e os conhecimentos populares (Pop.). A presença desses saberes pode ser considerada um ponto positivo, já que caracteriza uma abertura para trabalhos que discutam a temática ambiental de forma mais ampla e aprofundada, considerando sua complexidade.

Mesmo que outras formas de conhecimento pouco apareçam nas orientações 
educativas apresentadas pelos manuais, entende-se que a sua identificação pode sinalizar para a possibilidade de desenvolvimento de trabalhos que possam ser orientados pelo "diálogo de saberes", que, segundo Carvalho (2006, p.38), “[...] decorre não apenas da perspectiva interdisciplinar da temática ambiental, mas também do pressuposto de que diferentes formas de saber oferecem elementos significativos para a compreensão das relações sociedade-natureza [...]".

Outro ponto que merece ser destacado diz respeito às relações que se dão entre temática ambiental e ciência e tecnologia. Cabe salientar que os manuais valorizam os aspectos positivos do desenvolvimento da ciência e da tecnologia desconsiderando, frequentemente, suas contribuições para os processos de degradação ambiental. Por conta disso entende-se que os manuais devem ser mais cuidadosos no que se refere às relações mencionadas anteriormente, a fim de evitar a formação nos alunos e professores de uma visão neutra de ciência e tecnologia.

Outro ponto importante está relacionado à presença de temas controversos, dentre eles os relacionados às mudanças climáticas e aos organismos geneticamente modificados, que são identificados nas orientações de trabalho presentes nos manuais. Entende-se que os manuais poderiam, como sugerem Silva e Carvalho (2007), considerar de forma mais explícita as subjetividades, as incertezas e a complexidade que caracterizam os temas controversos.

Foi observado que as orientações educativas identificadas nos manuais dos professores apresentam uma preocupação em articular as diferentes formas de conhecimentos no que se refere ao tratamento das questões ambientais em sala de aula. É importante citar que Carvalho (2006), ao se referir aos conhecimentos, não está remetendo somente ao conhecimento produzido pela atividade científica. Outras formas de conhecimento que pretendam trabalhar as questões ambientais em sala de aula (como, por exemplo, o conhecimento produzido pela Filosofia) devem ser consideradas pelas propostas educativas. Nesse sentido, Santana (2005) chama a atenção para o fato de que as práticas educativas voltadas para a temática ambiental, que são planejadas e executadas no ambiente escolar, devem trabalhar o conhecimento e torná-lo pertinente.

A respeito da categoria dimensão dos valores, são identificadas, nas orientações presentes nos manuais dos professores, discussões relativas aos aspectos éticos (em todos os manuais), principalmente no que se refere às discussões relacionadas ao tema organismos geneticamente modificados. Ao considerar os valores éticos em suas propostas educativas, os manuais dão um importante passo no sentido de desenvolver novas formas de os seres humanos, organizados em sociedade, relacionarem-se com a natureza. Esse tipo de consideração está presente, de modo muito claro, em Carvalho (2006); é possível perceber que, de fato, ela precisa ser levada em consideração na elaboração de orientações educativas voltadas para o trabalho com as questões ambientais.

Os aspectos estéticos também são identificados nos manuais de quatro coleções (CSN, SF, N, FJM), sendo que as discussões levam em conta a beleza, o belo. Aqui, cabe ressaltar um ponto que pode ser explorado pelas propostas educativas voltadas à temática ambiental, que está relacionado à abordagem não só da dimensão estética relacionada à natureza, mas também à dimensão estética do trabalho científico que busca desvendar os mistérios do mundo que nos cerca (CARVALHO, 2006).

Ao trabalhar a questão ambiental na sala de aula, não é possível esquecer as complexas relações que se dão entre os indivíduos organizados em sociedade e destes com a natureza. Nesse sentido, considera-se importante a abordagem dos valores éticos 
e estéticos nos manuais dos professores, lembrando que esse tipo de abordagem ainda precisa ser mais bem desenvolvido nesses materiais.

Com relação à dimensão da participação política foram organizados quatro agrupamentos, apresentados no Quadro 4.

Quadro 4 - Presença dos agrupamentos relativos à dimensão da participação política nos manuais dos professores

\begin{tabular}{|l|c|c|c|c|}
\cline { 2 - 5 } \multicolumn{1}{c|}{} & \multicolumn{4}{c|}{ Agrupamentos } \\
\hline Coleções & Sustentabilidade & Cidadania & Legislação & $\begin{array}{c}\text { Identificação e resolução de problemas } \\
\text { ambientais }\end{array}$ \\
\hline SS & $\mathrm{X}$ & $\mathrm{X}$ & & $\mathrm{X}$ \\
\hline CSN & $\mathrm{X}$ & $\mathrm{X}$ & $\mathrm{X}$ & $\mathrm{X}$ \\
\hline ADN & $\mathrm{X}$ & $\mathrm{X}$ & $\mathrm{X}$ & $\mathrm{X}$ \\
\hline VJ & $\mathrm{X}$ & $\mathrm{X}$ & $\mathrm{X}$ & $\mathrm{X}$ \\
\hline JG & $\mathrm{X}$ & $\mathrm{X}$ & $\mathrm{X}$ & $\mathrm{X}$ \\
\hline SF & & & & $\mathrm{X}$ \\
\hline N & $\mathrm{X}$ & & $\mathrm{X}$ & $\mathrm{X}$ \\
\hline FJM & $\mathrm{X}$ & $\mathrm{X}$ & $\mathrm{X}$ & $\mathrm{X}$ \\
\hline
\end{tabular}

Ao se referir à sustentabilidade, a maior parte dos manuais apresenta a definição de desenvolvimento sustentável. Essas definições evidenciam aspectos ligados às questões econômicas. A natureza é vista simplesmente como fornecedora de mercadorias que devem ser exploradas pelos seres humanos, ou seja, a ideia de sustentabilidade apresenta uma relação bastante próxima com os objetivos do sistema capitalista. Portanto, o que se percebe é que, ao tratarem de sustentabilidade, os manuais reforçam a ideia de exploração dos recursos naturais sem questionar os interesses que existem por trás de tal ação.

Sobre o agrupamento denominado cidadania, identificam-se, nos manuais, referências à formação de cidadãos e ao desenvolvimento da cidadania. A ideia de formação cidadã está relacionada ao desenvolvimento de uma consciência a respeito dos problemas ambientais que se apresentam e à tomada de decisões diante dos mesmos. $\mathrm{O}$ que precisa ser considerado aqui é que nenhum manual deixa claro o que se entende pelos termos ou expressões cidadão, tomada de decisões e tomada de consciência. Elucidar esses termos ou expressões pode ajudar na elaboração e execução de práticas relacionadas à EA.

Com relação ao agrupamento legislação, identifica-se nos manuais a referência a diversos órgãos nacionais e internacionais relacionados à proteção e à fiscalização do meio ambiente. Os textos dos manuais, ao se referirem a esses órgãos, salientam a importância dos mesmos na elaboração de propostas de ação que possam contribuir com a preservação do meio ambiente. A utilização dos textos disponíveis nos manuais, que tratam de normas e leis relacionadas aos órgãos ambientais, pode auxiliar nas discussões relacionadas à legislação ambiental e privilegiar o caráter formativo e de sensibilização tanto dos professores quanto dos alunos.

Por fim, trata-se do agrupamento identificação e resolução de problemas ambientais. Nos manuais nos quais esse agrupamento foi identificado, percebe-se que a responsabilidade sobre a resolução dos problemas ambientais recai sobre o indivíduo, ou seja, o que se observa é que os manuais atribuem à reforma individual uma das principais alternativas de solução dos problemas ambientais. As ações coletivas assumem um importante papel na identificação das origens e consequências dos problemas ambientais e caracterizam-se como uma forma de enfrentamento de tais 
problemas. Com relação a esse agrupamento também é importante destacar a menção feita ao papel da educação, de um modo geral, e da educação ambiental, em particular, como forma de tratar das e propor soluções para os problemas relacionados às questões ambientais.

Ao se tratar da dimensão da participação política, deve-se salientar o papel da escola na formação de cidadãos capazes de transformar a realidade. Por isso, a dimensão política é considerada central nas propostas educativas voltadas para a temática ambiental. As diferentes abordagens que caracterizam os quatro agrupamentos apresentados no Quadro 4 podem ser compreendidas como um importante passo dos manuais, no sentido de trabalhar de maneira mais aprofundada, ou seja, focalizando não só os aspectos ambientais e científicos, mas também os políticos, econômicos, sociais relacionados às questões ambientais em sala de aula. Entende-se que se trata de um grande avanço no que diz respeito ao desenvolvimento de trabalhos relacionados à temática ambiental no ambiente escolar, porém não é possível deixar de pontuar que algumas questões ainda precisam ser mais cuidadosamente trabalhadas nas orientações presentes nos manuais com relação à dimensão da participação política. Esses materiais, por exemplo, apresentam um ser humano genérico como o responsável pelos problemas ambientais que as diferentes sociedades têm enfrentado. Como é apontado por Carvalho (2006, p.31), "[...] a interação do homem com a natureza está mediada por uma série de fatores historicamente determinados e que dependem da forma como as sociedades se organizam, tendo em vista a produção".

$\mathrm{Na}$ quarta categoria, relação entre as três dimensões, buscou-se identificar a relação entre as três dimensões da práxis humana que foram consideradas como referências na análise dos manuais dos professores. Pode-se dizer que não há, na maioria dos casos, orientações que deixem claro a relação entre elas.

A dimensão dos conhecimentos prevalece em relação às outras duas dimensões, e não são identificadas orientações ou atividades que deixem clara a importância da dimensão política, considerada como central no modelo proposto por Carvalho (2006) nas atividades que privilegiam a dimensão dos conhecimentos.

Com relação à dimensão dos valores, são identificadas nos manuais relações entre os valores éticos e os conceitos da biologia, principalmente no que se refere às abordagens relacionadas à genética, mais especificamente aos OGMs. Ao tratar da extinção de espécies, alguns manuais também possibilitam associar a dimensão dos conhecimentos à dimensão dos valores.

As orientações que mais se aproximam da possibilidade de um trabalho articulado entre as três dimensões são aquelas que propõem abordagens em uma perspectiva interdisciplinar. Isso porque, segundo reflexões a partir desta pesquisa, as propostas de atividades interdisciplinares, ao sugerirem a participação de disciplinas como a Geografia, a História, a Sociologia e a Filosofia, podem trazer para a discussão os aspectos relacionados às dimensões dos valores e da participação política. Mas é importante frisar que essas orientações não deixam essa articulação evidente.

Reconhece-se a importância dessa relação entre as três dimensões analisadas, mas é importante ressaltar que, ainda que seja de forma isolada, muitas das propostas de trabalho identificadas possibilitam o planejamento e a execução de bons trabalhos. Porém, esses trabalhos poderiam ficar mais completos e possibilitar uma compreensão mais ampla e aprofundada dos diferentes problemas ambientais caso estabelecessem a articulação entre as três dimensões.

Os temas polêmicos ou controversos identificados nas orientações presentes nos 
manuais também podem caracterizar uma orientação educativa que leve em consideração a relação entre as três dimensões da práxis humana, isso porque, como salienta Carvalho (2005, 2006), uma possibilidade de se planejar e desenvolver trabalhos educativos voltados à temática ambiental está relacionada ao trabalho com temas controversos e/ou com os conflitos socioambientais. A adoção desse princípio metodológico, segundo o autor, possibilita o questionamento e a desconstrução de determinados conceitos que têm sido assimilados de forma acrítica, dentre os quais podem ser citados o da harmonia nas relações sociedade-natureza, equilíbrio da natureza, visão holística.

\section{Considerações Finais}

A análise dos manuais dos professores de biologia aprovados no PNLD 2012 permitiu identificar que esses materiais apresentam pontos relevantes no que se refere ao trabalho com a temática ambiental no ambiente escolar. Dentre esses pontos é possível citar a valorização de trabalhos em uma perspectiva interdisciplinar para tratar das questões ambientais. Outro aspecto que chama a atenção é que, mesmo nas orientações e propostas educativas não apresentadas de forma explícita como interdisciplinares, nos manuais, há um esforço em tentar estabelecer uma articulação entre os conhecimentos das áreas das ciências naturais e os das ciências humanas. Foi observado, também, que as orientações educativas presentes nos manuais levam em consideração os valores éticos e estéticos no desenvolvimento de trabalhos com as questões ambientais em sala de aula.

A dimensão da participação política também foi identificada nos manuais dos professores, o que, segundo as reflexões a partir desta pesquisa, é essencial para trabalhos educativos com a temática ambiental. Sobre a relação entre as dimensões dos conhecimentos, dos valores e da participação política percebeu-se que os manuais apresentam algumas orientações educativas que promovem a articulação entre as três dimensões.

A identificação e reconhecimento de alguns temas ambientais como polêmicos ou controversos também possibilita uma abordagem mais aprofundada das questões ambientais pelos professores em sala de aula, já que esses temas promovem discussões nas quais diferentes opiniões são defendidas, fruto das subjetividades e incertezas que os caracterizam.

As orientações educativas relacionadas à temática ambiental, presentes nos manuais dos professores, mostram que as aulas de biologia constituem uma oportunidade de trabalhar com tal temática no ambiente escolar.

Todos esses pontos são relevantes e contribuem para a elaboração e execução de trabalhos relacionados à temática ambiental. Mas é importante dizer que os manuais precisam apresentar suas orientações educativas de maneira mais organizada, ou seja, essas orientações devem chamar a atenção dos professores para a complexidade que caracteriza as questões relacionadas à temática ambiental, sugerindo, por exemplo, trabalhos que articulem outras disciplinas do currículo, além da biologia, caracterizando assim abordagens mais amplas e aprofundadas, que possibilitem uma compreensão mais crítica de tais questões.

Dessa forma, entende-se que os trabalhos educativos com a temática ambiental podem contribuir com a formação de indivíduos capazes de tomar decisões responsáveis e conscientes, ou seja, que contribuam com uma formação crítica, passível de despertar, 
tanto nos professores quanto nos alunos, a percepção de que todos são agentes transformadores da realidade.

\section{Referências}

AMARAL, I. A.; MEGID NETO, J. Qualidade do livro didático de Ciências: o que define e quem define? Ciência \& Ensino, Campinas, n.2, p.13-14, Jun.1997.

BARDIN, L. Análise de Conteúdo. São Paulo: Edições 70, 2011.

BONOTTO, D. M. B. Conceitos e valores em Educação Ambiental: uma experiência com os alunos que não conseguiam juntar área verde e cidade. Holos Environment, Rio Claro, v.1, n.1, p.50-59, 2001.

BONOTTO, D. M. B. Educação Ambiental e Educação em Valores em um programa de formação docente. Revista Electrónica de Enseñanza de las Ciencias, v. 7, n. 2, p. 313-336, 2008. Disponível em: <http://reec.uvigo.es/volumenes/volumen7/ART3_Vol7_N2.pdf >. Acesso em: 16 out. 2012.

BONOTTO, D. M. B.; SEMPREBONE, A. Educação Ambiental e educação em valores em livros didáticos de ciências naturais. Ciência \& Educação, Bauru, v.16, n.1, p. 131-148, 2010.

CARVALHO, I. C. M. Educação Ambiental e Movimentos Sociais: elementos para uma história política do campo ambiental. Educação: Teoria e Prática, Rio Claro, v.9, n.16/17, p. 4656. Jan./Jun.; Jul./Dez. 2001.

CARVALHO, I. C. M. Educação ambiental: a formação do sujeito ecológico. 5 ed. São Paulo: Cortez Editora, 2011.

CARVALHO, L. M. A temática ambiental e a escola de $1^{\circ}$ grau. 1989. 286 f. Tese (Doutorado em Educação) - Universidade de São Paulo. São Paulo, 1990.

CARVALHO, L. M. A temática ambiental e o ensino de biologia: compreender, valorizar e defender a vida. In: MARANDINO, M.; SELLES, S. E.; SERRA, M.; AMORIM, A. C. (Orgs.). Ensino de biologia: conhecimentos e valores em disputa. Niterói: EDuff, 2005. p.85-99.

CARVALHO, L.M. A temática ambiental e o processo educativo: dimensões e abordagens. In: CINQUETTI, H.C.S.; LOGAREZZI, A. (Orgs.). Consumo e Resíduo - Fundamentos para o trabalho educativo. São Carlos: EdUFSCar, 2006. p.19-41. (Vol. 1).

CINQUETTI, H. C. S.; CARVALHO, L. M. As dimensões dos valores e da participação política em projetos de professoras: abordagens sobre os resíduos sólidos. Ciência \& Educação, Bauru, v.10, n.2, p.161-171, 2004.

GUIMARÃES, M. Educação Ambiental Crítica. In: BRASIL. Ministério do Meio Ambiente. Diretoria de Educação Ambiental. Identidades da educação ambiental brasileira. Brasília: MMA, 2004. p. 25-34.

KRASILCHIK, M. Reformas e realidade: o caso do ensino das ciências. São Paulo em Perspectiva, São Paulo, v.14, n.1, p.85-93, Jan./Mar. 2000.

MARPICA, N. S. As questões ambientais nos livros didáticos de diferentes disciplinas da 
quinta-série do ensino fundamental. 2008. 169 f. Dissertação (Mestrado em Educação) Universidade Federal de São Carlos. São Carlos, 2008.

MAULIN, G. C. A educação ambiental e a cidade: um espaço em construção? Interacções, Santarém, v.5, n.11, p. 67-90, 2009.

MORALES, A. G. M. Processo de institucionalização da educação ambiental. In: PARANÁ. Secretaria de Estado de Educação. Superintendência de Educação. Departamento da Diversidade. Coordenação de Desafios Educacionais Contemporâneos. Cadernos Temáticos da Diversidade Educação Ambiental. Curitiba: SEED - PR., 2008. (Vol. 1).

MOREIRA, M.A. Aprendizagem significativa: um conceito subjacente. Trabalho adaptado de Moreira, M.A., Caballero, M.C. e Rodríguez, M.L. (Orgs.). Actas del Encuentro Internacional sobre el Aprendizaje Significativo. Burgos, Espanha, 1997. p.19-44. Disponível em:< http://www.if.ufrgs.br/ moreira/apsigsubport.pdf>. Acesso em: 14 nov. 2014.

OLIVEIRA, E.; ENS, R. T.; ANDRADE, D. B. S. F.; MUSSIS, C. R. Análise de conteúdo e pesquisa na área da educação. Revista Diálogo Educacional, Curitiba, v. 4, n.9, p.11-27, Mai./Ago. 2003.

PAULILO, A. L. Os manuais do professor como fonte de pesquisa acerca da História ensinada. Relatório técnico. São Caetano do Sul: USCS, 2011. Disponível em: <http://repositorio.uscs.edu.br/bitstream/123456789/161/2/Os\%20manuais\%20do\%20professor $\% 20$ como\%20fonte\%20de\%20pesquisa.pdf>. Acesso em: 24 mai. 2012.

PEZZATO, J. P.; SILVA, J. M. A. P. A escola como espaço de ação política: uma análise à luz da ação-comunicativa de Habermas. Cadernos de Educação, Pelotas, n.31, p. 149-162, Jul./Dez. 2008.

RODRIGUES, N. Educação: da formação humana à construção do sujeito ético. Educação \& Sociedade, Campinas, v.22, n.76, p.232-257, Out. 2001.

SANTANA, L.C. Educação Ambiental: de sua necessidade e possibilidades. In: INTERNATIONAL WORKSHOP ON PROJECT BASED, 2005, Guaratinguetá. Papers... Guaratinguetá: PBL Tech, 2005.p.1-14. Disponível em:

<http://www.feg.unesp.br/ rioparaiba/palestras_pbl/Luiz\%20Carlos\%20Santana\%20artigo.pdf> . Acesso em: 10 ago. 2012.

SAUVÉ, L. Uma cartografia das correntes em educação ambiental. In: SATO, M.;

CARVALHO, I. (Orgs.). Educação Ambiental: pesquisas e desafios. Porto Alegre: Artmed, 2005. Disponível em: <

http://search.4shared.com/postDownload/iUu72shI/uma_cartografia_das_correntes_.html>. Acesso em: 3 abr. 2012.

SILVA, L. F.; CARVALHO, L. M. A temática ambiental e o processo educativo: o ensino de física a partir de temas controversos. Ciência \& Ensino, Campinas, v. 1, número especial, p.112, Nov. 2007.

SILVA, S. N.; SOUZA, M. L. O tema ambiente no livro didático de biologia: uma análise de conteúdo de três unidades temáticas. In: ENCONTRO PESQUISA EM EDUCAÇÃO AMBIENTAL, 6, Ribeirão Preto, 2011. Anais... Ribeirão Preto: USP, 2012. p. 1-12. Disponível em: <http://files.epea2011.webnode.com.br/200000071.../epea2011-0142-1.pdf〉. Acesso em: 
19 set. 2011.

VASCONCELOS, C.; PRAIA, J. F.; ALMEIDA, L. S. Teorias de aprendizagem e o ensino/aprendizagem das ciências: da instrução à aprendizagem. Psicologia Escolar e Educacional, Campinas, v. 7, n. 1, p.11-19, Jun. 2003.

VILA, A. J. T.; ABÍLIO, F. J. P. A temática ambiental nos livros didáticos de biologia do ensino médio: uma análise crítica reflexiva de 1990 a 2006. In: ENCONTRO DE INICIAÇÃO À DOCÊNCIA, 10, João Pessoa, 2008. Anais... João Pessoa: UFPB, 2008. p.1-7. Disponível em:

<http://www.prac.ufpb.br/anais/IXEnex/iniciacao/documentos/anais/5.MEIOAMBIENTE/5CE DMEPLIC01.pdf >. Acesso em: 13 jul. 2012.

VOICHICOSKI, M. S. R.; MORALES, A. G. Análise das pesquisas recentes (2000 a 2010): da relação entre educação ambiental e livro didático. Olhar de professor, Ponta Grossa, v.14, n.2, p.239-254. 2011.

Artigo recebido em 07/02/2014

Aceite em 12/11/2014 